\title{
Editorial
}

\section{Assessment in Action: Introduction to the Special Issue}

When College \& Research Libraries moved to a digital-only publishing model, one of our hopes was that we would be able to use the flexibility provided by that model to facilitate greater integration of content across the broader research and publication programs of the Association of College \& Research Libraries. While there are still many opportunities to pursue in terms of integrating content across $C \mathcal{E} R L, R B M$, ACRL monographs, and other Association publications, we are happy to present this special issue focused on the Assessment in Action (AiA) program as a step in the right direction.

As guest editors Kara J. Malenfant, Lisa Janicke Hinchliffe, and Debra Gilchrist describe in their introductory essay, AiA represents a path-breaking approach to ACRL sponsorship of research in our member libraries. Building on the call for action found in Megan Oakleaf's The Value of Academic Libraries: A Comprehensive Research Review and Report, the AiA program provided training, support, and a community of practice for librarians (and others) conducting research having both strategic value to the Association, as well as local value to its members. ${ }^{1}$ My own institution was part of the first cohort of the AiA program, and the research conducted by our team promoted greater collaboration between the library assessment effort and the complementary efforts of our colleagues in Academic Affairs and Student Affairs. ${ }^{2}$ Our experience mirrors those you will see described in the essays included in this collection and it is safe to say that our participation in AiA had a meaningful impact on the design and delivery of information literacy instruction in our first-year-experience program. ${ }^{3}$

In addition to their demonstration of local "value," the seven essays included in this collection are notable for the way in which they demonstrate the impact of the Association's investment in providing research training and support to members in a diverse array of institutions, including community colleges, liberal arts colleges, comprehensive universities, and research universities. While each experience is unique and tied to the institutional culture and concerns of each participating institution, the AiA program helps us to see the power of undertaking a shared research program across multiple institutions. ${ }^{4}$ Finally, AiA participation has encouraged members to share research results across conferences, poster sessions, and other publications, and the ACRL Value of Academic Libraries Committee has included profiles of AiA projects on its blog. ${ }^{5}$ Most recently, ACRL has created a comprehensive bibliography of AiA-related presentations and publications, and even a cursory review shows that the impact of this project on research and practice in our field is considerable (and ongoing). ${ }^{6}$

We hope that the Association will continue to learn from the experience of the Assessment in Action program, appreciate the meaningful contributions to research and practice documented in these essays, and find ways to support similar initiatives in the future as the demand for evidence-based decision making and demonstrated impact on student learning in libraries will only continue to rise. We look forward to seeing collections of work produced by those future projects featured in special issues of $C \mathcal{E R} L$ yet to come. 


\section{Notes}

1. Megan Oakleaf, The Value of Academic Libraries: A Comprehensive Research Review and Report (Chicago: Association of College \& Research Libraries, 2010), accessed October 26, 2015, http:// www.ala.org/ala/mgrps/divs/acrl/issues/value/val_report.pdf.

2. Heather Jagman, "Grant Research Provides Insight into First Year Students' Library Experience," (March 3, 2015), accessed October 26, 2015, http://news.library.depaul.press/faculty/2015/03/03/grant-research-provides-insight-into-first-year-students-library-experience/.

3. Paula R. Dempsey and Heather Jagman, "'I Felt Like Such a Freshman': First-Year Students Crossing the Library Threshold," portal: Libraries and the Academy 16, no. 1 (2016): 89-107.

4. Similar benefit was seen on a smaller scale in the ERIAL Project (http://www.erialproject. org/), which resulted in numerous studies, including those collected in: Lynda M. Duke and Andrew D. Asher, eds., College Libraries and Student Culture: What We Now Know (Chicago: American Library Association, 2012).

5. For an overview of early AiA activities and reports, see: Association of College \& Research Libraries, Academic Library Contributions to Student Success: Documented Practices from the Field (Chicago: Association of College \& Research Libraries, 2015), accessed October 26, 2015, http:// www.ala.org/acrl/files/issues/value/contributions_report.pdf. For ongoing project profiles, see: Association of College \& Research Libraries, ACRL Value of Academic Libraries [Web log], accessed October 29, 2015, http://www.acrl.ala.org/value/?cat=25.

6. Association of College \& Research Libraries, Assessment in Action Bibliography, accessed January 5, 2016, http://www.acrl.ala.org/value/?page_id=980. 